\title{
Cloud Computing in IoT based Smart Meter
}

\author{
Somalina Chowdhury, Santanu Kumar Sen
}

\begin{abstract}
Modern tends forces a massive change in power industry and utility value chain. Therefore demands of resources and storage is also increases which can be supported by cloud computing. Consumer role becomes one of the vital role here. These are all implemented by Smart Grid. So we need to develop advanced power distribution grids with modern infrastructure. In this paper we will discuss about one of the most important component of smart grid that is smart meter that will IoT based and use cloud platform for data processing and storing. Cloud infrastructure will help in building a large number of application on it and also helps in storing large volume of data. Cloud technology enhances the storage on demand using virtual memory concept. Thus provides an economic, portable, scalable infrastructure.
\end{abstract}

KEYWORDS: Smart grid, Cloud infrastructure, smart metering infrastructure, IoT, GSM, Wi-Fi, webpage

\section{INTRODUCTION}

Smart Grid becomes smarter when IoT is introduced to it. Smart meter in smart grid also uses this technology. Sensors are part of smart meter consists IoT technology use to collect Raw data after every fixed interval of time may be 15 min then transforms it in big data[1] and stores it. In some countries they have implemented this infrastructure. In this paper, we mainly focus on processing of huge amount of data in proper and efficient way with the help of cloud. Cloud provides resource on demand that is visualization of data is supported by it. Thus it saves energy, increase portability, and makes it cost effective and reliable. Electric transmission and distribution system modernization is very much needed to improve energy deficiency. The Smart grid with IoT delivers efficient, stable and safe bidirectional system. Renewable energy or alternative energy also used here for power generation [2].Cloud computing becomes an integral part of Smart meter as it excellently managing the huge data with least effort and high utilization of physical memory. There are various cloud infrastructure available viz- Azure, Microsoft Azure, Amazon Web Services (AWS), Alibaba Cloud, IBM Cloud, SAP etc. One of the vital part of cloud computing is routing and congestion control algorithm [3]. Cloud computing systems and smart grid are connected through data centres. We will mainly focus on the cloud database to store smart meter data.

\section{RELATED WORK}

Today consumption of energy is one of the basic concern and it gets complimented if it Cloud computing is vast recourse that can store large volume of data as per requirement of the data store in big data.

Revised Manuscript Received on October 20, 2020.

* Correspondence Author

Somalina Chowdhury*, Assistant Professor Principal Dept. of Computer Application, GNIT

Prof. (Dr.) Santanu Kumar Sen, Assistant Professor Principal Dept. of Computer Application, GNIT

(c) The Authors. Published by Blue Eyes Intelligence Engineering and Sciences Publication (BEIESP). This is an open access article under the CC BY-NC-ND license (http://creativecommons.org/licenses/by-nc-nd/4.0/)
But implementation of this concept must be done with proper security [4][5]. The cloud infrastructure has scalability, interoperability and flexibility. It also helps in integrating distribution of power system and transform it to automated one. Here not only power distribution, but control and management of entire system with reconfiguration and other cloud services is also initiated here [6]. In old metering system, a person monthly visits every house in a locality to check the electricity meter for collecting the electricity consumption. Sometimes this bill was not properly calculated. Overbilled problem was quite a common feature here. To overcome this problem there need a single bidirectional secure communication is needed. IoT with Arduino helps to build this system as efficient in energy consumption as they consume less power and work faster. The GSM system can be implemented to give proper information and website is also created to provide reports in graphical format [7]. Cloud computing can also combine with Big Data to manage the entire energy consumption system in smart grid effectively. Data analysis and processing both can be done more effectively with these two technologies [8].

\section{METHODOLOGY}

In this paperour primary goal is to see vast amount of data used in smart meter must be properly collected and thenanalyse and process them in cloud atmosphere. The main goal is create a pyramid structure of cloud infrastructure to provide different types of computer services and information. But the most important feature is the security concern in the communicational network.

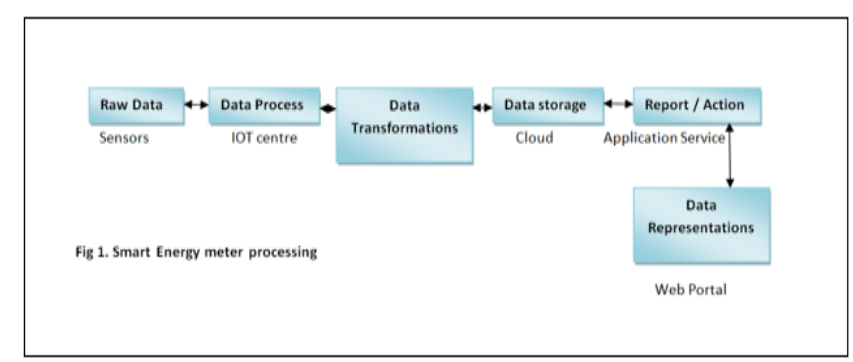

A. Smart Grid and Smart meter

Smart Grid is adopted by many countries like Canada, Italy, and Portugal etc. Smart Grid can becomes smarter by implementing IoT in them and other components among which the most important one is smart meter. Smart grids are bidirectional in nature. So they can through back excess energy in the grid when not needed or customer as well as the utility both can communicated between them. Smart meter is a mainly designed meter with IoT devises, wireless sensors, arduino. Quick customer response is one of the vibrant features of this system.

Published By:

Blue Eyes Intelligence Engineering and Sciences Publication

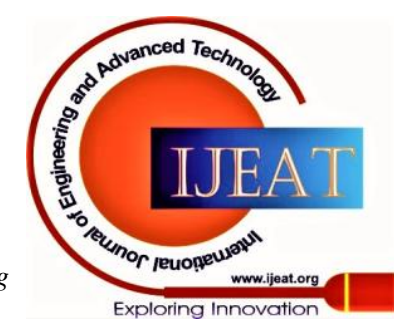

DOI:10.35940/ijeat.A1891.1010120 


\section{Cloud Computing in IoT based Smart Meter}

\section{B. Big data in smart grid}

Smart meter produce vast data is difficult to handle by normal data structure and data base system. This is stored inform of big data. Big data has its own V structure.

That is Volume as ithandles large amount of data, Velocity as the data comes in every 15 min interval, Variety of data reaches at every hr, Veracity and Value as it changes at every intervals. This big data infrastructure helps in proper collection of data so that they can be analysed in proper way and thereafter process to get actual information in welldefined represent able format.

\section{Cloud Computing}

Cloud computing is a process of data storage as per requirement of the customer or the utility. Cloud haspyramid structure of data centres for big data analysis and data management. A security structure is also integrated with it for better performance. There are many countries using the cloud infrastructure but large scale implementation is always a big issue. High management with economy. The pyramid structure contains sky view, regional view and user view. Sky view for managing devises, regional view for managing data and smart meter,user view managing customers.Cloud computing gives various services categoriesas:

- infrastructure as a service (IaaS)

- platform as a service (PaaS)

- $\quad$ software as a service (SaaS)

- FaaS (functions as a service)

Cloud computing has various types of development models:

- Public Cloud

- PrivateCloud

- HybridCloud

- CommunityCloud

D. Proposed Process

Smart meter along with big data can be used in Smart grid to improve its performance. There are many advantages of using cloud infrastructure but some process we have to follow for the betterment of the system

- Every utility and customer must have unique id and their data must be encrypted and process or store

- Fault protection is designed so that if fault occur in some portion then minimum area will get effected

- Active grid management is done by using IoT technique

- Power flows backward if excess

Real time data privacy provided for user and utility both

\section{RESULT AND DISCUSSION}

In this paper, we have introduced how cloud computing included with Smart meter of Smart Grid technology. Here cloud infrastructure is discussed one in service basis and one in development basis. Smart meter uses mainly private cloud due to security aspect. By applying this concept we can work with real time data which is vast in volume and can get graphical representation of information through application. For this purpose we have used android app.

\section{CONCLUSION}

In near future smart grid will become one of the most popular energy consumption technique and hopefully many other countries where till now smart grid is not implemented will also try this infrastructure. In upcoming days we will try to implement this setup in localities to fulfil green energy project where conservation of the energy will be the main aim.

\section{REFERANCES}

1. Nikhil Mishra, Vinay Kumar, Garima Bhardwaj, "Role of Cloud Computing in Smart Grid", publication at: https://www.researchgate.net/publication/334765912

2. P. Siano, C. Cecati, C. Citro, and P. Siano, "Smart operation of wind turbines and diesel generators according to economic criteria," IEEE Trans. Ind. Electron., vol. 58, no. 10, pp. 4514-4525, Oct. 2011

3. R. H. Katz, "Tech Titans Building Boom," IEEE Spectrum, pp. 40 54, Feb. 2009.

4. Nikhil Mishra, Vinay Kumar, Garima Bhardwaj , "Role of Cloud Computing in Smart Grid," publication at: https://www.researchgate.net/publication/334765912

5. SomalinaChowdhury, Santanu Kumar Sen, "Security in Smart Meter using Iot", in IJEAT, ISSN: 2249 - 8958, Volume-9 Issue-4, April 2020

6. Marco Paua, Edoardo Pattib, Luca Barbieratob, Abouzar Estebsaric, Enrico Ponsc, Ferdinanda Poncia, Antonello Montia, "A Cloud-based Smart Metering Infrastructure for Distribution Grid Services and Automation" submitted to Sustainable Energy, Grids and Networks August 9, 2017

7. Birendrakumar Sahani, Tejashree Ravi, Akibjaved Tamboli , Ranjeet Pisal, " IoT Based Smart Energy Meter", in IRJET Volume: 04 Issue: 04 | Apr -2017

8. Yang Zhang, Tao Huang and Ettore Francesco Bompard," Big data analytics in smart grids: a review ", in Zhang et al. Energy Informatics (2018) https://doi.org/10.1186/s42162-018-0007-5

\section{AUTHORS PROFILE}

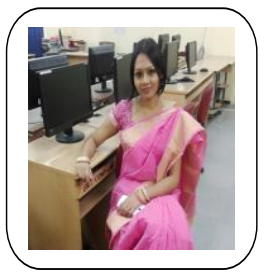

SomalinaChowdhury, More than 8 years of experience in the field of Computer Application. Pursuing $\mathrm{PhD}$ in Computer Science and Engg.(CSE)/Information Technology(IT) from MAKAUT, West Bengal since Dec 2018. Completed MCA and BCA from MAKAUT in 2008 \&2011 respectively. Member of Institution of Engineers (India).Received Believers Award from National Program on Technology Enhanced Learning (NPTEL) for completion of four courses in a single semester. One patent is filed. Presently working as Assistant Professor in Guru Nanak Institute of Technology (GNIT), Kolkata since 2011. Awarded for organizing Smart India Hackathon, 2019. Areas of working interest are IoT, Cloud Computing, Big Data and Genetic algorithm, Network Security, Cryptography and Wireless Sensor Network. Around 9 papers in international journal among them one in IJEAT.

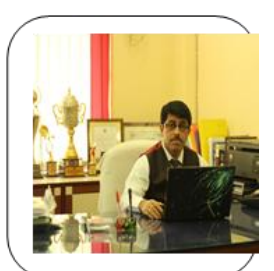

Prof. (Dr.) Santanu Kumar Sen, Around 25 years of experience (8 years in Industry and 17 years in Engineering Academia including Abroad). PhD (Engg.), MBA, M.Tech, B.E Chartered Engineering. Professional Engineer, FIET (in process), UK Fellow: FIETE, FIE, SMIEEE, USA Senior Member- (SMCSI), India Life Member LMISTE, India Senior MemberMACM, USA.Awarded the 1st Professional Engineer Degree under Computer Science Division from IE in 2019. Expert Member of International Professional Engineering under CS from IE in 2019 Board Member of WBJEEB since 2015Advisor, National Cyber Security Cell, New Delhi.RashtriyaShikshaGouravPuroskar from Centre. "Bharat BibhushanSammanPuraskar" from EHRDA, New Delhi in 2013 Research Paper Publications: 70+ Patents filed and Published: 6 Work Experience: Presently working as Principal of Guru Nanak Institute of Technology Guru (An Autonomous Degree Engineering College) since 2012.

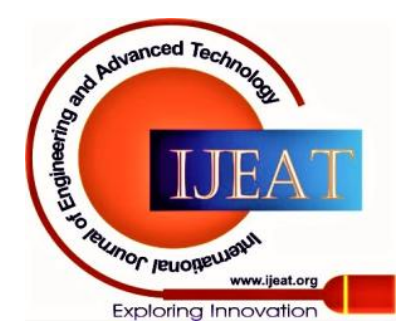

